\title{
PERAN FORUM KERUKUNAN UMAT BERAGAMA DALAM MENINGKATKAN KUALITAS SIKAP HIDUP TOLERANSI ANTAR UMAT BERAGAMA DI KOTA KUPANG
}

\author{
Nimrod Frebdes Taopan ${ }^{1}$, Petrus Ly' ${ }^{2}$, Leonard Lobo ${ }^{3}$ \\ 1,2,3 Pascasarjana Universitas Nusa Cendana, Kupang, Indonesia \\ 1taopanbobby7@gmail.com \\ 2lypetrus@yahoo.co.id \\ 3loboleonard667@yahoo.com
}

\begin{abstract}
ABSTRAK
Penelitian ini dilaksanakan dengan tujuan: Mendeskripsikan program kerja FKUB sebagai bentuk usaha meningkatkan kualitas sikap toleransi. Mendeskripsikan hambatan dalam mengimplementasikan program Kerja FKUB. Mendeskripsikan upaya mengatasi hambatan dan Mendeskripsikan kualitas sikap toleransi antar umat beragama di Kota Kupang. Metode yang digunakan dalam penelitian ini adalah metode kualitatif bersifat deskriptif, teknik pengumpulan data berupa wawancara dan studi dokumen. Hasil penelitian ini menunjukan bahwa:1) Peran FKUB NTT dalam membangun toleransi umat beragama di Kota Kupang dilakukan dengan program rutin dalam bentuk dialog, seminar, sosialisasi, lomba pidato serta lomba Hyme dan mars kerukunan, program tidak rutin dalam bentuk penerbitan buku, pembuatan striker, kalender dan spanduk keagamaan. 2) Terdapat hambatan berupa kesibukan dari pemuka agama sehingga rapat belum berjalan secara baik, komunikasi dalam rapat juga hanya terjadi setiap ada rapat dan terbatasnya fasilitas serta Pemerintah maupun masyarakat belum menyadari peran dari FKUB NTT.3) Upaya mengatasi hambatan dilakukan dengan diskusi antar badan pengurus, komunikasi dengan pemerintah, sosialisasi, membuat proposal dan menghemat dana sesuai dengan kebutuhan.4) Kerukunan di Kota Kupang berjalan dengan baik tanpa ada konflik keagamaan disebabkan kerukunan yang ada di Kota Kupang merupakan warisan dari leluhur yang terus dijaga dan dikembangkan hingga saat ini.

Kata Kunci: Peran, Forum Kerukunan Umat Beragama, Toleransi Beragama
\end{abstract}


Jurnal Pendidikan Pancasila dan Kewarganegaraan

Volume I Nomor I (Juni) 2020

\begin{abstract}
This research was conducted with the aim of: describing the FKUB work program as an effort to improve the quality of tolerance. Describe the obstacles in implementing the FKUB Work program. Describe efforts to overcome barriers and Describe the quality of tolerance among religious people in Kupang City. The method used in this research was qualitative methods, data collection techniques in the form of interviews and document studies. The results of this study indicated that: 1) The role of the NTT FKUB in building religious tolerance in Kupang City was carried out with routine programs in the form of dialogue, seminars, socialization, speech competitions and hyme competitions and harmony marriages, non-routine programs in the form of book publishing, striker making, religious calendars and banners. 2) There are obstacles in the form of busy religious leaders, so the meeting has not run well, communication at meetings only occurs when there are meetings and limited facilities. The government and the community are not aware of the role of NTT FKUB. 3) conducted with discussions between the governing body, communication with the government, socialization, making proposals and saving funds in accordance with needs.4) Harmony in Kupang City runs well without any religious conflict due to the existing harmony in the city of Kupang is a legacy of the ancestors who continue to be guarded and developed to date.

Keywords: Role, Religious Harmony Forum, Religious Tolerance
\end{abstract}

\title{
PENDAHULUAN
}

Indonesia adalah negara yang ditandai oleh berbagai agama, bahasa, suku, budaya dan adat istiadat. Kemajemukan ini tidak hanya membuat negara Indonesia menarik, unik dan kaya akan tradisi (multikultural), tetapi juga multi-agama (Yusri, 2008). Indonesia terdiri dari pulau-pulau besar dan kecil. Setiap pulau dan wilayah memiliki kebiasaan dan karakteristiknya sendiri. Ini tercermin dalam moto "Persatuan dalam Keragaman" (meskipun berbeda) di Republik Indonesia.

Ketika Indonesia beralih dari rezim otoriter ke era reformasi. Konflik horizontal dan vertikal dengan nuansa keagamaan sering terjadi, baik dari perbedaan agama maupun disebabkan oleh perbedaan etnis (Ali, 2003; Budyatna \& Ganiem, 2011). Ini bisa terjadi ketika kontradiksi terjadi. Orang Indonesia menjalani kenyataan ini selama sejarah mereka (Afif, 2013 p12). Ketentuan pasal 29 UUD 1945 sangat penting karena menjamin keikutsertaan masyarakat dalam beragama dan beriman. Untuk bertemu dan memperkaya kehidupan orang-orang. Semua orang percaya menjalankan agama mereka sesuai dengan ajaran agama mereka dan memiliki kesempatan untuk menciptakan kehidupan beragama (Munawar: 2005; Depag, 2007; Nisvilyah, 2013).

Pada kenyataannya, masyarakat multikultural seperti pisau bermata 
Jurnal Pendidikan Pancasila dan Kewarganegaraan

Volume I Nomor I (Juni) 2020

dua. Ia bukan hanya kekuatan (modal sosial) tetapi juga ancaman yang bisa membahayakan integrasi negara. Jika keragaman ini dipertimbangkan dan dipelihara dengan baik, itu akan menjadi berkat yang dapat mempromosikan pengembangan kreativitas, kekayaan intelektual, dan pengampunan bangsa (Hatimah, 2008: 71). Sebaliknya, dalam masyarakat multikultural, jika pemikiran sosial selalu diterima oleh sifat prasangka, kebencian dan keraguan (kesadaran timbal balik) terhadap orang yang berbeda, ikatan sosial yang kuat dibangun dan akan dimungkinkan (Widjaja, 2010). Ini menyebabkan kontradiksi secara primitif. Konflik yang sering terjadi dan kekerasan sosial cenderung menimbulkan ancaman serius bagi integrasi rakyat Indonesia.

Baru-baru ini, konflik yang muncul di Indonesia bahkan telah menjadi catatan sejarah yang kelam, termasuk konflik sosial, konflik etnis, konflik keluarga, konflik etnis dan agama, nuansa keagamaan (Soekanto, 2010). Pemahaman yang saling bertentangan tentang menjadi ranting atau sifat dasar yang harus diselesaikan dengan cara yang damai bukanlah cara yang keras dan penuh kekerasan. Suatu kontradiksi dengan nuansa keagamaan, seperti pembubaran Ahmadiyah di Tasikmalaya, Situbondo, Pekalongan, Poso Ambon, Cikeas, dan peristiwa-peristiwa di Sunnigani di Sampang Madura, telah dipicu oleh rasa aman dan ketenangan pikiran yang berbeda (Yewangoe, 2002).

Catatan konflik gelap tentang intoleransi agama, khususnya pada 30 November 1998, ketika kota Kupang berkonflik dengan orang-orang Kristen dan Muslim disertai dengan penghancuran berbagai tempat ibadah (Suryana, 2011). Duka dan perilaku solidaritas diprakarsai oleh kelompokkelompok pelajar muda dan Kristen seperti Gerakan Mahasiswa Kristen Indonesia (GMKI), Asosiasi Pelajar Katolik Republik Indonesia (PMKRI), Pemuda Nusa Tenggara Katolik Timur (NTT), pelajar Kupang, dll. itu. Kerumunan kemudian menuju masjid-masjid Muslim di desa-desa Bonipoi dan Sorol, setelah penghancuran masjid-masjid Kupan, karena masalah gereja yang terbakar. Sebagai akibat dari kemarahan besar 30 November, setidaknya 11 masjid, sebuah masjid dan beberapa rumah dan toko-toko Muslim rusak. Kemarahan tidak berhenti pada 30 November. Dua hari kemudian, pada tanggal 1 dan 2 Desember 1998, kerusuhan masih terjadi dan menyebabkan kerusakan. Di antara sasaran Mass Amock adalah rumah-rumah milik kepresidenan Uniform Development Party (PPP), masjid, dan toko-toko Bugis (http: //conflict-social-amuk-massa-dikupang.html).

Kota Kupang, ibukota provinsi Nusa Tenggara Timur, memiliki 
Jurnal Pendidikan Pancasila dan Kewarganegaraan

Volume I Nomor I (Juni) 2020

populasi yang heterogen. Ada empat jenis kepercayaan yang diadopsi oleh penduduk Kota Kupang yang diakui secara sah oleh negara: Protestan, Katolik, Muslim, Hindu, dan Budha. Melalui dialog atau dialog di mana Gereja Indonesia (PGI) dan perwakilan umat Buddha Indonesia (WALUBI) mencapai kesepakatan tentang prinsip-prinsip panduan dan membentuk koalisi bersama menteri agama dan perdana menteri setempat dan mencapai kesepakatan. Wakil kepala daerah, yang bertugas menjaga kerukunan umat beragama, memberdayakan forum kerukunan umat beragama (FKUB) untuk mendirikan tempat ibadah (Kirom, 2015).

Masalah dan kontradiksi dalam menciptakan tempat ibadah di Kota Kupang antara 2011 dan 2016 terjadi, termasuk penciptaan Masjid Nuru Musaphil di Batu Prat. Warga Batu Prat dan beberapa anggota Dewan Perwakilan Rakyat Daerah (DPRD) menolak untuk mendirikan masjid karena mereka tidak mengikuti evolusi prosedur. Hal ini dinyatakan dalam surat yang diketuai oleh Dewan Perwakilan Rakyat Kota Kupang (DPRD) mengenai penghentian sementara pendirian masjid sehingga tidak timbul perselisihan sambil menunggu situasi atau situasi lebih lanjut. yg menguntungkan. Forum Agama dan Harmonisasi Kota Kupang (FKUB) juga aktif terlibat dalam penyebaran program dan peraturan terkait kerukunan umat beragama (terutama tokoh agama). Akibatnya, para pemimpin lokal akan memahami tujuan program dan aturan kerukunan umat beragama.

Harapannya adalah agar para pemimpin dan komunitas agama dapat mengimplementasikan program dan aturan yang selaras dengan agama dalam kehidupan komunitas yang majemuk. Legitimasi komunitas dan pemerintah seperti itu sangat membantu dalam menjaga stabilitas dan dinamika kehidupan beragama yang harmonis. Karena menciptakan dan memelihara kerukunan beragama adalah tanggung jawab bersama (Nasir, 2012).

\section{METODE PENELITIAN}

Penelitian ini termasuk jenis penelitian kualitatif. Penelitian ini merupakan bentuk penelitian lapangan deskriptif yang menggambarkan apa itu atau gambaran yang lebih jelas tentang peran forum kerukunan umat beragama dalam forum (FKUB) dalam meningkatkan kualitas toleransi. Pihak terkait dan informen dalam penelitian ini adalah Ketua, wakil ketua, sekretaris dan anggota FKUB Provinsi Nusa Tenggara Timur, Ketua MUI, Ketua Klasis/Sinode, Keuskupan agung Kupang, Ketua Parisada Hindu darma Kupang, ketua Walubi. Teknik Pengumpulan data 
Jurnal Pendidikan Pancasila dan Kewarganegaraan

Volume I Nomor I (Juni) 2020

yang dilakukan dalam penelitian ini melalui wawancara, dokumentasi. Teknik analisis data yang digunakan dalam penelitian ini adalah simbolik model interkaktif. Menurut (Sugiyono, 2012:92) model ini memiliki tiga komponen yaitu Reduksi data, Penyajian data dan penarikan kesimpulan.

\section{HASIL DAN PEMBAHASAN}

Menurut (Sukardi, 2000) menyatakan bahwa program merupakan salah satu hasil kebijakan yang penetapannya melalui proses panjang dan disepakati oleh para pengelolanya untuk dilaksanakan. Menurut Ibu Maria sebagai Ketua FKUB NTT Dalam Pelaksanaan dan penyusunan programprogram kerja dari FKUB NTT dibagi dalam dua program kerja antara lain Pertama Program Rutin, program ini dilakukan sesuai tugas dan tanggung jawab bedasarkan Peraturan Bersama Menteri Agama dan Menteri Dalam Negeri (PBM) No. 9 dan 8 Tahun 2006 (Syaukani, 2008). Program yang di terapkan FKUB NTT disepakati bersama melalui rapat serta diskusi sehingga program yang di selenggarakan tepat sasaran dan menjadi tolak ukur kerukuan umat beragama di Kota Kupang dalam bentuk dialog, seminar, sosialisasi dan lomba pidato serta lomba Hyme dan mars kerukunan. Program kerja rutin dariFKUB NTT dilaksanakan dari bulan Februari-November dan semua program diharapkan tepat sasaran kepada seluruh masyarakat Kota Kupang dalam membina toleransi dan kerukunan dimulai bukan sejak dewasa melainkan sejak dini toleransi ditanamkan. Kedua Program tidak rutin, Program FKUB NTT ini dilaksanakan bedasarkan proposal yang ditujukan kepada pemerintah Nusa Tenggara Timur melalui dana hibah dan jika disetujui barulah program ini terlaksana secara baik, jika tidak disetuju maka dananya dikurangi dari permintaan bedasarkan proposal sehingga dalam pelaksanaan program ini tidak bersifat rutin artinya program ini dilaksanakan bedasarkan dana hibah yang diberikan oleh pemerintah melalui proposal program.Program tidak rutin dalam bentuk penerbitan buku, pembuatan striker, kalender dan spanduk keagamaan.

FKUB NTT dalam pelaksanaan program mengalami beberapa hambatan baik hambatan yang datang dari FKUB itu sendiri (interen) yaitu Belum maksimalnya komunikasi antar Pengurus dalam menjalankan fungsinya sebagai bagian dari organisasi, Kurangnya fasilitas penunjang pelaksanaan kegiatan dan Keterbatasan team pelaksana dalam keanggotaan FKUB yang terdiri dari berbagai lintas agama sedangkan Hambatan atau kendala eksteren FKUB NTT antara lain Dana yang sangat minim yaitu sekitar 50 juta per tahun namun tahun lalu naik 60 juta dari 
Jurnal Pendidikan Pancasila dan Kewarganegaraan

Volume I Nomor I (Juni) 2020

Kementrian Agama, di tambah dari kesbangpol dalam bentuk kegiatan 1 atau 2 kegiatan dan ditambah dana hibah dari pemerintah melalui berbagai usulan proposal.Ada beberapa kegiatan atau program yang mendapatkan dana dari luar. Contohnya jalan kerukunan yang melibatkan semua instansi, dana yang didapatkan adalah sponsor dari POLDA NTT sehingga untuk mewujudkan visi dan misinya pengurus FKUB harus rela mengorbankan tenaga dan materinya, Program Kerja dari kesbangpol NTT sebagai pemerintah hanya melibatkan FKUB jika ada rapat dan turun ke masyarakat hanya waktu pilkada, Pemerintah selalu beranggapan bahwa FKUB hanya sebagai pemadam kebakaran yang artinya ada masalah mengenai keagamaan dulu baru FKUB turun tangan sebenarnya dalam pelaksanaanya bukan seperti hal tersebut, Kesadaran masyarakat akan dialog belum cukup dewasa, hampir setiap orang jika mengalami konflik akan berfikir menuju pengadilan dan ingin menang, Keberadaan FKUB sebagai lembaga kerukunan dan pengaduan belum banyak diketahui oleh masyarakat.

Upaya atau solusi dari FUKB NTT dalam mengatasi hambatan baik hambatan interneal maupun eksternal dalam program kerja dilakukan dengan berbagai langkah-langkah antara lain Mendorong para tokoh agama agar selalu melakukan diskusi secara intern dan eksteren mengenai kerukunan agar umat tidak hanya melihat program tapi juga mendengarkan diskusi dari para tokoh agama guna meningkatkan toleransi umat beragama di Kota Kupang, FKUB selalu membangun komunikasi dengan pemerintah baik melalui komunikasi pribadi, komunikasi publik maupun kelompok agar memberikan support dana yang maksimal sesuai dengan Peraturan Bersama Menteri Agama dan Menteri Dalam Negeri (PBM) No. 9 dan 8 Tahun 2006, Memaksimalkan setiap dana yang diberikan pemerintah dengan melihat program unggulan yang lansung menyentuh masyarakat guna memaksimalkan toleransi umat beragama, Membuat proposal kepada Pemerintah dengan berbagai penjelasan bahwa setiap program yang diberikan bermanfaat untuk kepentingan masyarakat dalam meningkatkan toleransi, Menjalin kerja sama dengan pemerintah daerah, kepolisian dan ormas-ormas keagamaan yang ada di Kota Kupang dan Membangun pemahaman masyarakat melalui sosialisasi akan pentingnya FKUB dalam membangun kualitas kerukuan yang tinggi sebagai contoh bagi provinsi ataupun kab/kota lain di Indonesia.

Kerukunan atau toleransi di Kota Kupang merupakan warisan leluhur yang tumbuh dari dalam pribadi manusia atau individu, bisa dilihat dari 
Jurnal Pendidikan Pancasila dan Kewarganegaraan

Volume I Nomor I (Juni) 2020

kawin mawin berbeda agama islam nikah dengan Kristen ataupun sebaliknya, tetapi kenapa akhir-akhir ini keagaman menjadi persoalan sebenarnya itu merupakan budaya dari luar yang memprovokasi dan mempengaruhi masyarakat. Menurut Ibu Pdt Litelnoni di GMIT beberapa tahun terakhir melakukan kegiatan Jambore PAR tingkat sinode anak-anak sudah diperkenalkan untuk mengunjungi rumah-rumah ibadah dan GMIT pernah membuat suatu terobasan yaitu mengundang umat muslim untuk buka puasa bersama di kantor Sinode GMIT kita menyediakan air wuduh untuk sholat dan menyediakan makanan halal untuk umat muslim jadi bukan hanya dengan ceramah saja tetapi aksi nyata dilakukan.

Selama ini tidak ada masalah keagamaan cuman masalah tahun 1998 yang terjadi diluar tetapi imbasnya di NTT dan untuk sekarang tidak pernah ada masalah mengenai agama di Kota Kupang. Kerukunan terjadi bila saling mengerti hal ini yang terjadi dikota Kupang, terjadi dialog yang menjadi tolak ukur contohnya Toa dari umat Muslim terjadi dialog di beberapa masjid untuk bisa mengecilkan suara dan itu bisa diterima umat muslim sampai sekarang tidak ada masalah. Hal menarik dari Kota Kupang yang tidak dimiliki daerah lainnya yaitu Kalau mayoritas penduduk NTT adalah Kristen, tidak ada tirani terhadap minoritas. Bahkan sampai saat ini, ketika daerah-daerah lain saling sandera soal keberagamaan, tidak ada satu pun tempat ibadah yang dibakar massa di NTT masyarakat Kota Kupang tidak pernah terpengaruh dengan isu agama atau isu radikalisme. Sikap toleransi harus dipertahankan terutama pemuda-pemudi sebagai penerus bangsa jika pemuda meniru hal yang positif dari orangtua mengenai kerukunan pasti kerukunan dan toleransi di Kota Kupang akan terus terjaga.

Toleransi nyata dan terbukti di Kota Kupang yang tidak ada didaerah lain yaitu pendirian rumah ibadah agama Budha dalam pembangunan rumah ibadah mendapat respon positif dimana tanah yang diberikan merupakan tanah hibah dari pemerintah Kota Kupang dan masyarakat bersama-sama bekerja bersama dalam proses pembangunan. Keterwakilan dari agama Budha dalam pengurus FKUB NTT yang sebenarnya tidak bisa karena jumlah penganut yang sedikit. Pihak FKUB NTT juga memberikan gedung FKUB lantai 3 yang digunakan untuk beribadah setiap hari Minggu.

\section{KESIMPULAN}

Peran Forum Kerukunan Umat beragama (FKUB) Nusa Tenggara Timur dalam membangun toleransi umat beragama di Kota Kupang 
Jurnal Pendidikan Pancasila dan Kewarganegaraan

Volume I Nomor I (Juni) 2020

dilakukan dengan berbagai program kerja baik program rutin dalam bentuk dialog, seminar, sosialisasi dan lomba pidato serta lomba Hyme dan mars kerukunan maupun program tidak rutin dalam bentuk penerbitan buku, pembuatan striker, kalender dan spanduk keagamaan. Dalam pelaksanaan program kerja Peran Forum Kerukunan Umat beragama (FKUB) Nusa Tenggara Timur terdapat hambatan berupa kesibukan dari pemuka agama sehingga rapat belum berjalan secara baik, komunikasi dalam rapat juga hanya terjadi setiap ada rapat dan terbatasnya fasilitas serta Pemerintah maupun masyarakat belum menyadari peran dari Peran Forum Kerukunan Umat beragama (FKUB) Nusa Tenggara Timur dalam membina serta menumbuhkan kesadaran akan kerukunan umat beragama di Kota Kupang. Upaya mengatasi hambatan dilakukan dengan diskusi antar badan pengurus dan komunikasi.

merintah, sosialisasi, membuat proposal dan menghemat dana sesuai dengan kebutuhan. Kerukunan di Kota Kupang berjalan dengan baik tanpa ada konflik keagamaan disebabkan kerukunan yang ada di Kota Kupang merupakan warisan dari leluhur yang terus dijaga dan dikembangkan hingga saat ini.

\section{DAFTAR PUSTAKA}

Afif Muhammad (2013). Agama dan Konflik Sosial. Bandung: Marja

Ali M. (2003). Teologi Pluralis Multikultural: Menghargai Kemajemukan Menjalin Kebersamaan. Jakarta: Penerbit Kompas.

Budyatna, M dan Ganiem, L.M .(2011).Teori Komunikasi Antar Pribadi. Jakarta: Kencana.

Depag RI. (2007). Bingkai Teologi Kerukunan Hidup Umat Beragama Di Indonesia. Jakarta: Badan Penelitian dan Pengembangan Agama Proyek Peningkatan Kerukunan Umat Beragama di Indonesia.

Kirom, A. (2015). Peranan Forum Kerukunan Umat Beragama (FKUB) Dalam Merawat Kehidupan Umat Beragama: Studi Atas Fkub Bantul Yogyakarta. Tesis. Yogyakarta: UIN Sunan Kalijaga.

Munawar, S. Agil (2005). Fikih Hubungan Antar Umat Beragama. Jakarta: Ciputat Press.

Nasir, F. N (2012). Strategi Pendidikan Upaya Memahami Wahyu dan Ilmu Yogyakarta: Pustaka Pelajar

Nisvilyah, L (2013). Toleransi Antarumat Beragama Dalam Memperkokoh Persatuan dan Kesatuan Bangsa (Studi Kasus Umat Islam Dan Kristen Dusun Segaran Kecamatan Dlanggu Kabupaten Mojokerto). Kajian Moral dan Kewargenegaraan, 2 (1). 
Jurnal Pendidikan Pancasila dan Kewarganegaraan

Volume I Nomor I (Juni) 2020

Soekanto, S. (2010). Sosiologi Suatu Pengantar. Jakarta: Rajawali Prers

Sugiyono. (2012). Metode Penelitian Kuantitatif Kualitatif dan RED. Bandung: Alfabeta.

Suryana, Toto. (2011). Konsep dan Aktualisasi Kerukunan Antar Umat Beragama. Jurnal Pendidikan Agama Islam Ta'lim, 9(22).

Syaukani, Imam. (2008). Kompilasi Kebijakan Dan Peraturan Perundang-Undangan Kerukunan Umat Beragama. Jakarta: Puslitbang.

Widjaja. (2010). Komunikasi: Komunikasi dan hubungan masyarakat. Jakarta: Bumi Aksara

Yewangoe.A.A. (2002). Agama dan Kerukunan. Gunung Mulia: Jakarta.

Yusri, M. F. M. (2008). Prinsip Pendidikan Multikulturalisme dalam Ajaran Agama-agama di Indonesia. Jurnal Kependidikan Islam, 3 (2). 